\title{
im DETAIL
}

Ausstellen und Präsentieren

Museumskonzepte Markeninszenierung Messedesign
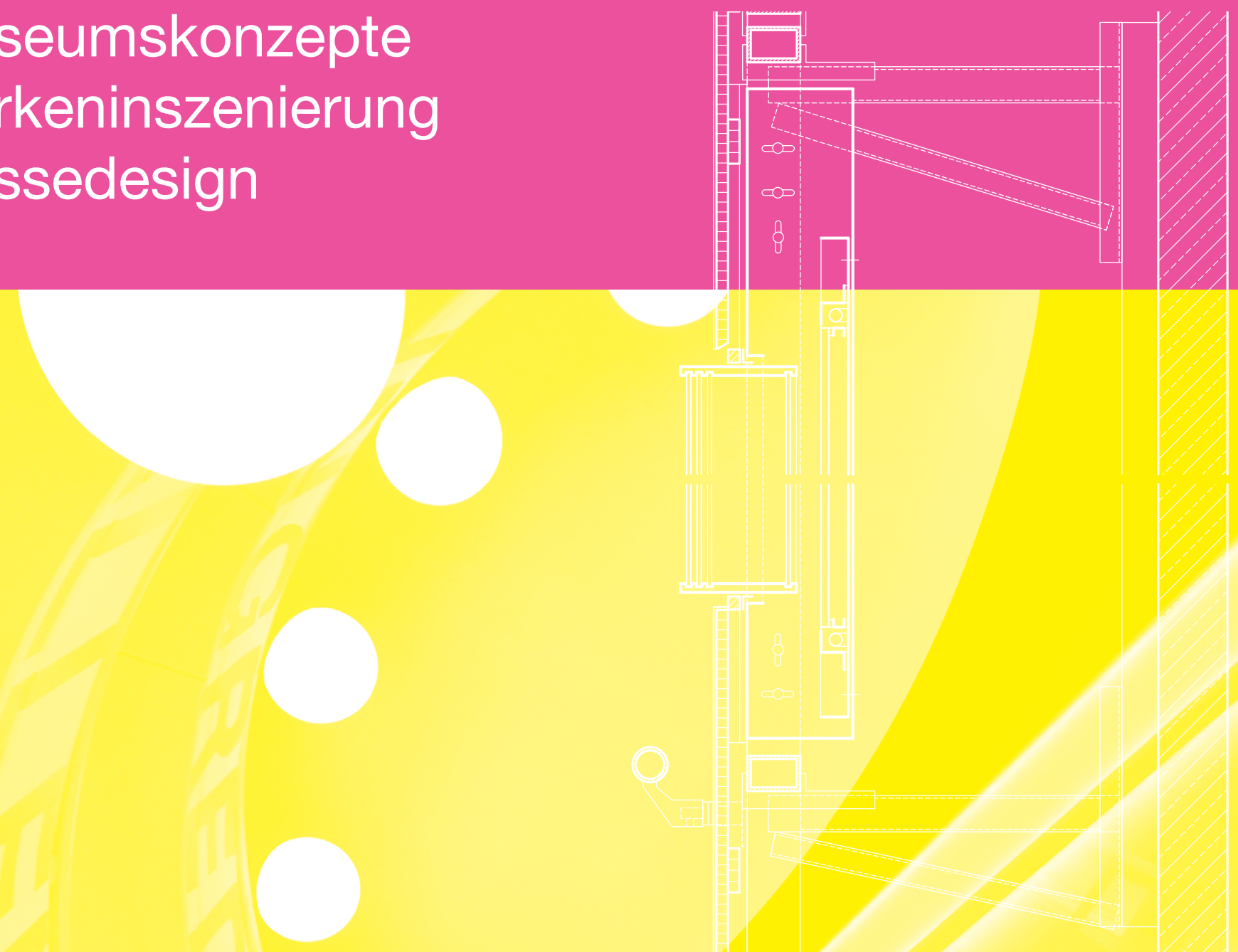

im DETAIL Ausstellen und Präsentieren 

im DETAIL

Ausstellen und Präsentieren

Museumskonzepte

Markeninszenierung

Messedesign

Christian Schittich (Hrsg.) 
Herausgeber: Christian Schittich

Projektleitung: Steffi Lenzen

Redaktion und Lektorat: Sandra Leitte, Cosima Strobl

Redaktionelle Mitarbeit: Carola Jacob-Ritz, Michaela Linder,

Daniela Steffgen, Melanie Weber

Zeichnungen: Melanie Denys, Ralph Donhauser,

Martin Hemmel, Caroline Hörger, Nicola Kollmann,

Simon Kramer, Elisabeth Krammer, Dejanira Ornelas

DTP: Roswitha Siegler, Simone Soesters

Ein Fachbuch aus der Redaktion DETAIL

Dieses Buch ist eine Kooperation zwischen Edition Detail - Institut für

internationale Architektur-Dokumentation GmbH \& Co. KG und

Birkhäuser Verlag AG

Bibliografische Information der Deutschen Nationalbibliothek

Die Deutsche Nationalbibliothek verzeichnet diese Publikation

in der Deutschen Nationalbibliografie; detaillierte bibliografische Daten

sind im Internet über

$<$ http://dnb.d-nb.de> abrufbar

Dieses Buch ist auch in englischer Sprache erhältlich

(ISBN: 978-3-7643-9955-9).

๑ 2009 Institut für internationale Architektur-Dokumentation GmbH \& Co. KG,

Postfach 3306 60, D-80066 München und

Birkhäuser Verlag AG, Basel · Boston · Berlin, Postfach 133, CH-4010 Basel

Dieses Werk ist urheberrechtlich geschützt. Die dadurch begründeten Rechte, insbesondere die der Übersetzung, des Nachdrucks, des Vortrags, der Entnahme von Abbildungen und Tabellen, der Funksendung, der Mikroverfilmung oder der Vervielfältigung auf anderen Wegen und der Speicherung in Datenverarbeitungsanlagen, bleiben, auch bei nur auszugsweiser Verwertung, vorbehalten. Eine Vervielfältigung dieses Werks oder von Teilen dieses Werks ist auch im Einzelfall nur in den Grenzen der gesetzlichen Bestimmungen des Urheberrechtsgesetzes in der jeweils geltenden Fassung zulässig. Sie ist grundsätzlich vergütungspflichtig. Zuwiderhandlungen unterliegen den Strafbestimmungen des Urheberrechts.

Gedruckt auf säurefreiem Papier, hergestellt aus chlorfrei gebleichtem Zellstoff $($ TCF $\infty)$.

Printed in Germany

Reproduktion:

Martin Härtl OHG, München

Druck und Bindung:

Kösel GmbH \& Co. KG, Altusried-Krugzell

ISBN: 978-3-7643-9954-2 